\title{
International parquet adhesives standard
}

$T^{\text {h }}$ he publication of the international standard for parquet adhesives ISO 17178 allowed the German adhesives industry to take the advancing state of the art with regard to parquet adhesives into account on a global level too. This new standard is the result of the active cooperation of the German adhesives industry in the national standardisation platform ISO - in this case assisted to a significant extent by the experts from the Technical Commission on Construction Adhesives (TKB)).

The new ISO standard is based on DIN EN 14293 “Adhesives - Adhesives for the bonding of parquet to a subfloor - Test procedures and minimum requirements" which was successfully established some years ago. It describes tests and defines minimum requirements for hard, hard elastic and

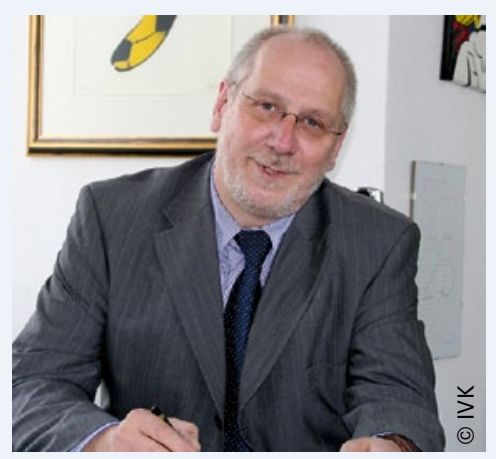

- for the first time ever - soft elastic parquet adhesives. This classification now takes the development of elastic parquet adhesives based on SMP and PUR into account on an international level too. On the German market, these adhesives systems have al-
Ansgar van Halteren, CEO of the German Adhesives Association (IVK): "The active expert supervision - on a national and international level - of the content of adhesives-related standardisation projects is a significant instrument of the strategy pursued by the German Adhesives Association, which is to fruitfully support the constantly increasing internationalisation of its member companies and the business as a whole."

most completely replaced the parquet adhesives with a high solvent content which were usual for a time. The new international standard should therefore be good news for manufacturers, craftsmen and all those responsible for health and safety.

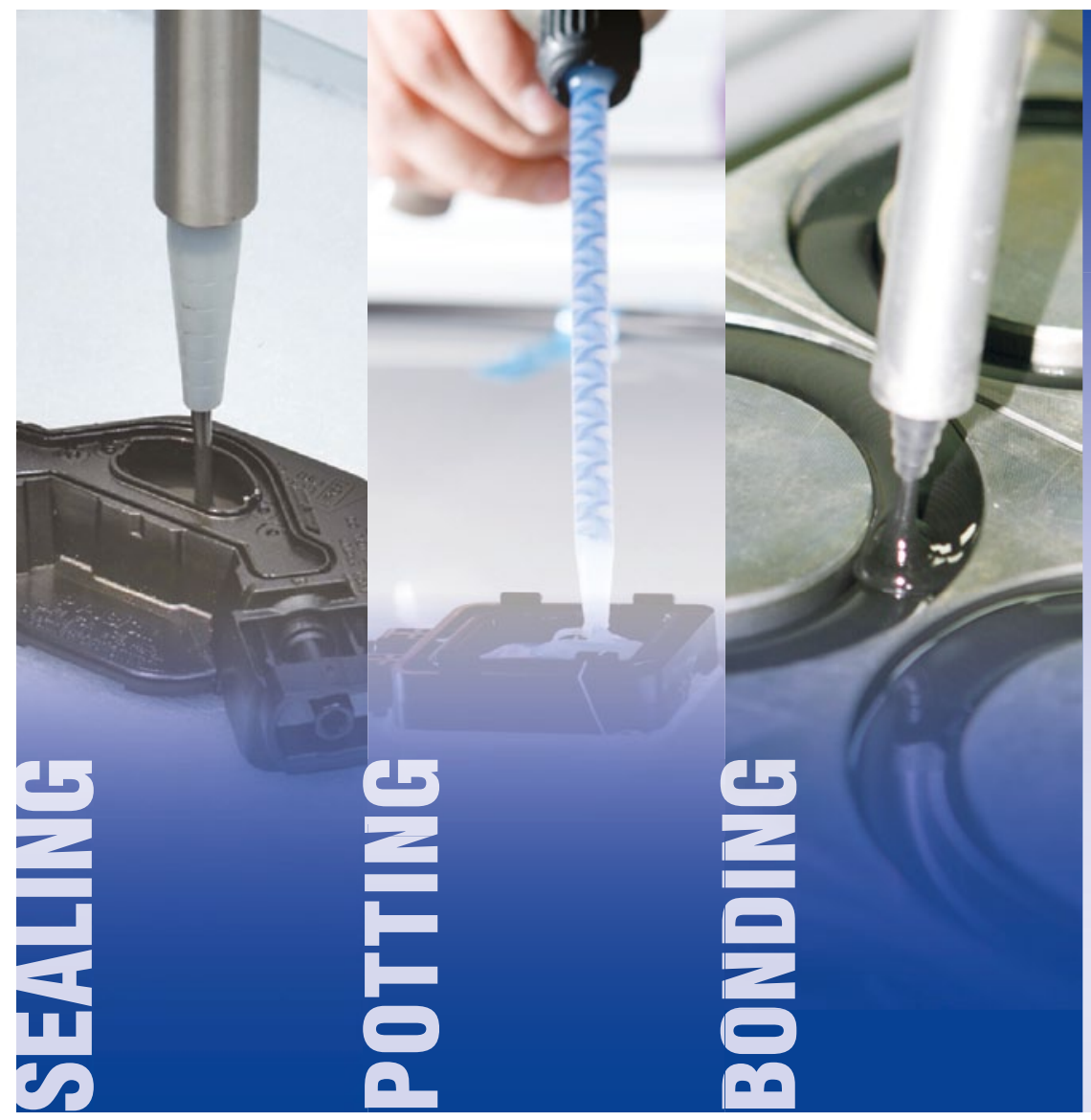

\section{A GrACo}

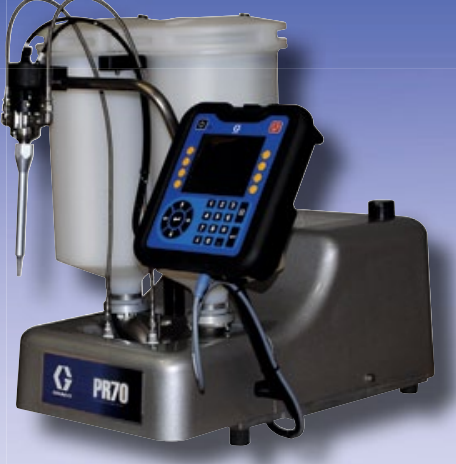

\section{PR70 $^{\text {TM }}$}

Meter Mix and dispense system for 2 components for Epoxy Sealants, Utheranes, Adhesives, Silicones, and more

Contact us to see how the PR70 can simplify your life :

pr70.33.graco.eu.com

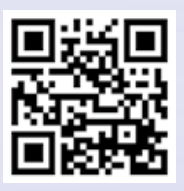

